\title{
Inhibition of BRD4 inhibits proliferation and promotes apoptosis of psoriatic keratinocytes
}

\author{
Xiaohui Sun ${ }^{1}$ and Pengfei Yang ${ }^{2^{*}}$
}

\author{
*Correspondence: \\ yangpengfeif@163.com \\ 2 Department \\ of Dermatology, The \\ First Affiliated Hospital \\ of Shandong First Medical \\ University \& Shandong \\ Provincial Qianfoshan \\ Hospital, Jinan Clinical \\ Research Center for Tissue \\ Engineering Skin \\ Regeneration and Wound \\ Repair, 16766 Jingshi Road, \\ Jinan 250014, Shandong, \\ China \\ Full list of author information \\ is available at the end of the \\ article
}

\begin{abstract}
Background: Psoriasis is a common chronic recurrent inflammatory skin disease. The pathogenesis of psoriasis, such as other autoimmune diseases, is still unclear, which brings great difficulties to the treatment. This study aimed to investigate the role of bromine domain protein 4 (BRD4) in affecting the psoriatic keratinocytes.
\end{abstract}

Methods: Imiquimod-induced psoriasis mice model and TNF-a or IL-17A induced HaCAT cells, an experimental model in vitro for psoriasis, were constructed. The pathological skin changes at the back of mice were observed by hematoxylin and eosin (H\&E) assay and evaluated by psoriasis area and severity index (PASI). KI67 expression and keratinocyte apoptosis at the skin tissues were, respectively, detected by Immunohistochemical analysis and TUNEL assay. The inflammatory factors in mice serum and culture supernatant were determined by ELISA assay. The related proteins expression of proliferation, apoptosis and MAPK pathway were detected by Western blot analysis.

Results: BRD4 expression was upregulated in injured skin on the back of imiquimodinduced mice and (+)-JQ1 relieved the skin injury by suppressing the inflammation and promoting apoptosis of keratinocytes. Consistently, BRD4 expression was also increased in TNF-a or IL-17A induced HaCAT cells. (+)-JQ1 suppressed the viability and inflammation, and promoted apoptosis of TNF-a or IL-17A induced HaCAT cells. In addition, the MAPK signaling pathway was inhibited by (+)-JQ1 whether in mice or HaCAT cells.

Conclusions: Inhibition of BRD4 inhibited proliferation and inflammation and promoted apoptosis of psoriatic keratinocytes.

Keywords: BRD4, Proliferation, Apoptosis, Psoriatic keratinocytes

\section{Background}

Psoriasis is a chronic inflammatory skin disease. About $2 \%$ of adults worldwide suffer from psoriasis, which can cause itching, silvery scales and swollen erythema, and can lead to complications of depression. Psoriasis is also associated with many diseases, such as hypertension, diabetes and metabolic syndrome [1-3]. Physiologically, the manifestations of psoriasis vulgaris include epidermal hyperkeratosis and paraceratosis, vascular author(s) and the source, provide a link to the Creative Commons licence, and indicate if changes were made. The images or other third party material in this article are included in the article's Creative Commons licence, unless indicated otherwise in a credit line to the material. If material is not included in the article's Creative Commons licence and your intended use is not permitted by statutory regulation or exceeds the permitted use, you will need to obtain permission directly from the copyright holder. To view a copy of this licence, visit http:// creativecommons.org/licenses/by/4.0/. The Creative Commons Public Domain Dedication waiver (http://creativecommons.org/publicdomain/zero/1.0/) applies to the data made available in this article, unless otherwise stated in a credit line to the data. 
distortion, and dermal inflammatory infiltration [4]. However, the pathogenesis of psoriasis is still unclear. Current systematic treatment measures for psoriasis include methotrexate (MTX), cyclosporin A, auxin, biologics, and sometimes steroids for patients with moderate to severe psoriasis, but these drugs have obvious side effects and adverse reactions, such as bone marrow suppression, abnormal liver function and metabolic disorders [5]. Therefore, it is urgent to explore new effective therapeutic drugs for psoriasis.

Bromine domain protein 4 (BRD4) is the most widely studied member of the bromodomain and extra-terminal (BET) family, which contains two tandem bromine domains (BD1, BD2) and one extra-terminal domain (ET) [6]. BRD4 induces activation or inhibition of target genes by recruiting different transcriptional regulators throughout the cell cycle [7] and, meanwhile, regulates DNA replication, cell cycle gene transcription and other cell activities [8]. A study has shown that BRD4 has pro-inflammatory effects [9]. In cerebral ischemia-reperfusion injury, BRD4 inhibition can reduce glial cell activation and inhibit inflammatory release [10]. In the spinal cord injury model, BRD4 inhibition attenuates the inflammatory response of microglia [11]. BRD4 inhibition can alleviate the vincristine-induced peripheral neuropathy by suppressing inflammation and oxidative stress [12]. However, there are few studies on BRD4 in psoriasis which is a chronic inflammatory disease. Only one study has shown that miR-125 can inhibit the expression of BRD4 through Notch signaling in psoriasis [13]. However, the specific effect of BRD4 inhibition on psoriasis is still unknown.

Studies have shown that inhibition of BRD4 can inhibit MAPK signal and reduce spinal cord ischemia reperfusion injury [11] and inhibition of BRD4 can inhibit the expression of MAPK signaling pathway in diabetic intervertebral disc degeneration [14]. Therefore, this study aims to continue to explore whether BRD4 inhibition can affect MAPK signaling pathway in psoriasis. In addition to an animal model, a cell model also used in this study can be more fully verify the regulatory effect of BRD4 inhibition on MAPK signaling pathway.

Imiquimod-induced psoriasis mice model and TNF- $\alpha$ or IL-17A induced HaCAT cells, an experimental model in vitro for psoriasis [15], were constructed to explore the effect of BRD4 inhibition on psoriasis and the specific mechanism about MAPK pathway.

\section{Results}

BRD4 expression was upregulated in injured skin on the back of imiquimod-induced mice

The skin was damaged on the back of mice induced by imiquimod for 7 days compared with control group (Fig. 1A). As shown in Fig. 1B, the dorsal epidermis of psoriasis mice was hyperplasia and thickened, mainly due to the increased number of spinous layer cells, accompanied by hyperplasia of dermal collagen fibers, red staining, and dense infiltration of dermal inflammatory cells. BRD4 expression was increased in injured skin tissues compared with control group (Fig. 1C).

\section{(+)-JQ1 weakened the skin injury on the back of imiquimod-induced mice}

The skin was seriously damaged on the back of mice induced by imiquimod for 7 days, and (+)-JQ1 or methotrexate could effectively alleviate the keratoderma injury on the back of imiquimod-induced mice (Fig. 2A). Compared with the Model group, the epidermis of the (+)-JQ1 group was significantly thinner, the collagen fibers of the dermis were 




sparse, and the inflammatory cells were less. The epidermis of methotrexate-treated mice was close to the histological changes of the epidermis of normal mice (Fig. 2B). KI67 expression was highly expressed in skin tissue samples of mice in Model group, which was decreased by the treatment of (+)-JQ1 or methotrexate (Fig. 2C). PASI score $(6.4 \pm 0.55)$ was the highest in Model group and $(+)-J Q 1$ or methotrexate could reduce the PASI score (Fig. 2D).

\section{(+)-JQ1 decreased the release of inflammatory factors in serum and increased the apoptosis of keratinocytes of imiquimod-induced mice}

The levels of inflammatory factors (IFN- $\gamma$, IL-8 and IL-6) in serum of imiquimodinduced rat were increased and (+)-JQ1 or methotrexate could suppress the inflammation (Fig. 3A). The expression of p-p65/p65 and IkBa in serum of imiquimod-induced rat was also upregulated, which was decreased by (+)-JQ1 or methotrexate (Fig. 3B). TUNEL assay indicated that apoptosis of keratinocytes was almost not happened in imiquimod-induced mice, which was enhanced by (+)-JQ1 or methotrexate (Fig. 3C). As shown in Fig. 3D, the bcl2 expression was increased, while the expression of bax, Cleaved caspase3/total caspase3 and Cleaved caspase9/total caspase9 was decreased in skin tissues of imiquimod-induced mice, which was partially reversed by (+)-JQ1 or methotrexate.

\section{(+)-JQ1 suppressed the MAPK signaling pathway in imiquimod-induced mice}

The expression of p-p38/p38, p-JNK/JNK and p-ERK/ERK in skin tissues of imiquimodinduced mice was increased, which was suppressed by the treatment of (+)-JQ1 or methotrexate (Fig. 4). 


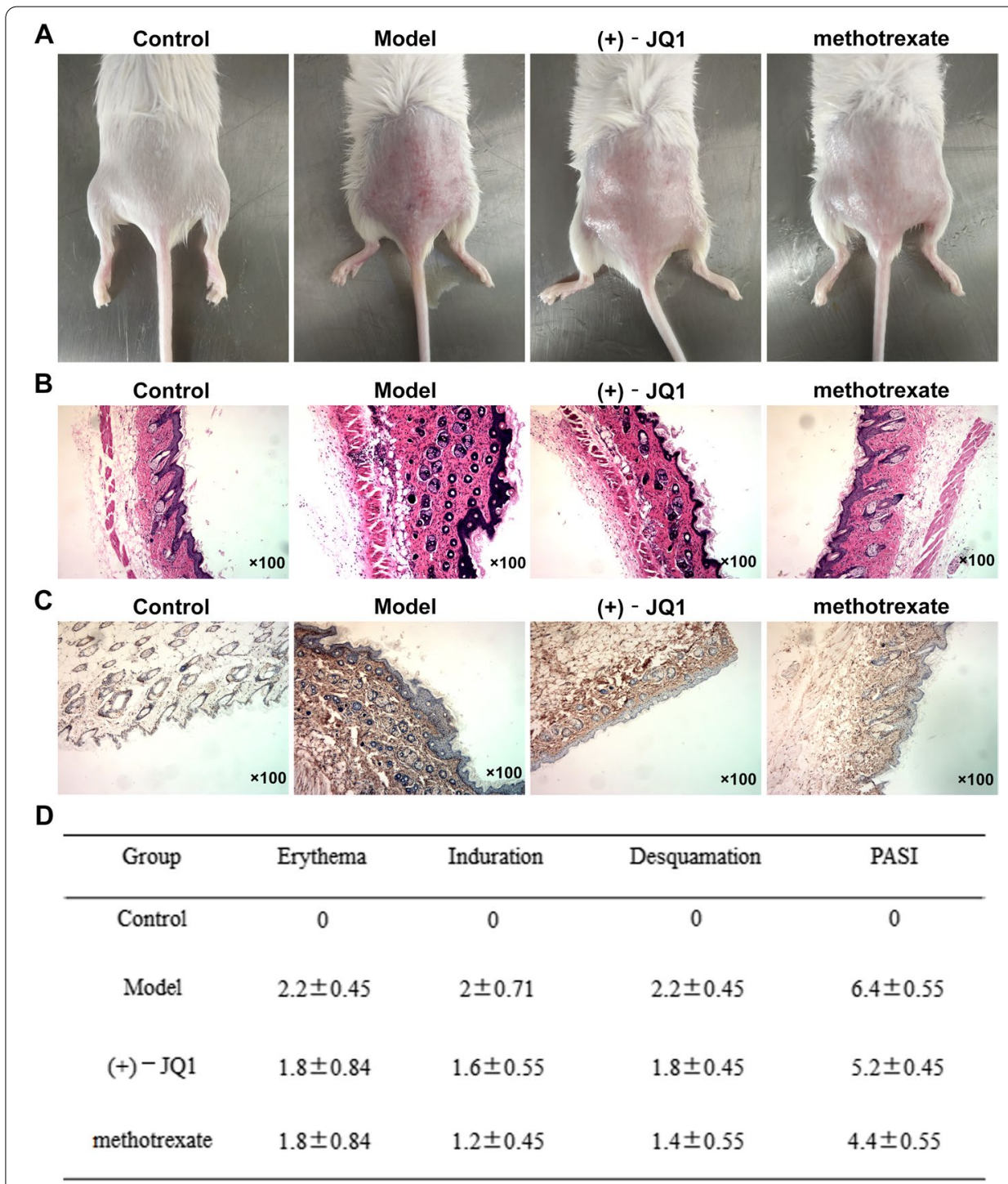

Fig. 2 (+)-JQ1 weakened the skin injury on the back of imiquimod-induced mice. A Skin on the back of mice was photographed. B Pathological changes of skin on the back of mice was observed by HE staining. C KI67 expression in skin tissues on the back of mice was detected by Immunohistochemical analysis. D Degree of skin lesions in psoriasis was evaluated by PASI

BRD4 expression was increased in HaCAT cells induced by TNF- $a$ or IL-17A

After HaCAT cells induced by TNF- $\alpha$, BRD4 expression was gradually increased from 10 to $50 \mathrm{ng} / \mathrm{ml}$ (Fig. 5A). Similarly, BRD4 expression was gradually increased in HaCAT cells treated with IL-17A from $10 \mathrm{ng} / \mathrm{ml}$ to $50 \mathrm{ng} / \mathrm{ml}$ (Fig. 5B). $100 \mathrm{ng} / \mathrm{ml}$ TNF- $\alpha$ or IL17A has no obvious effect on BRD4 expression compared with $50 \mathrm{ng} / \mathrm{ml}$ TNF- $\alpha$ or IL17A. Therefore, $50 \mathrm{ng} / \mathrm{ml}$ TNF- $\alpha$ or IL-17A was selected for subsequent experiment.

(+)-JQ1 suppressed the viability of HaCAT cells induced by TNF- $a$ or IL-17A

The viability of HaCAT cells induced by TNF- $\alpha$ or IL-17A was increased and (+)JQ1 suppressed the viability of the TNF- $\alpha$ or IL-17A induced HaCAT cells from 50 to $100 \mathrm{nM}$ (Fig. 6A, B). Therefore, $100 \mathrm{nM}$ (+)-JQ1 was chosen for next experiment. 


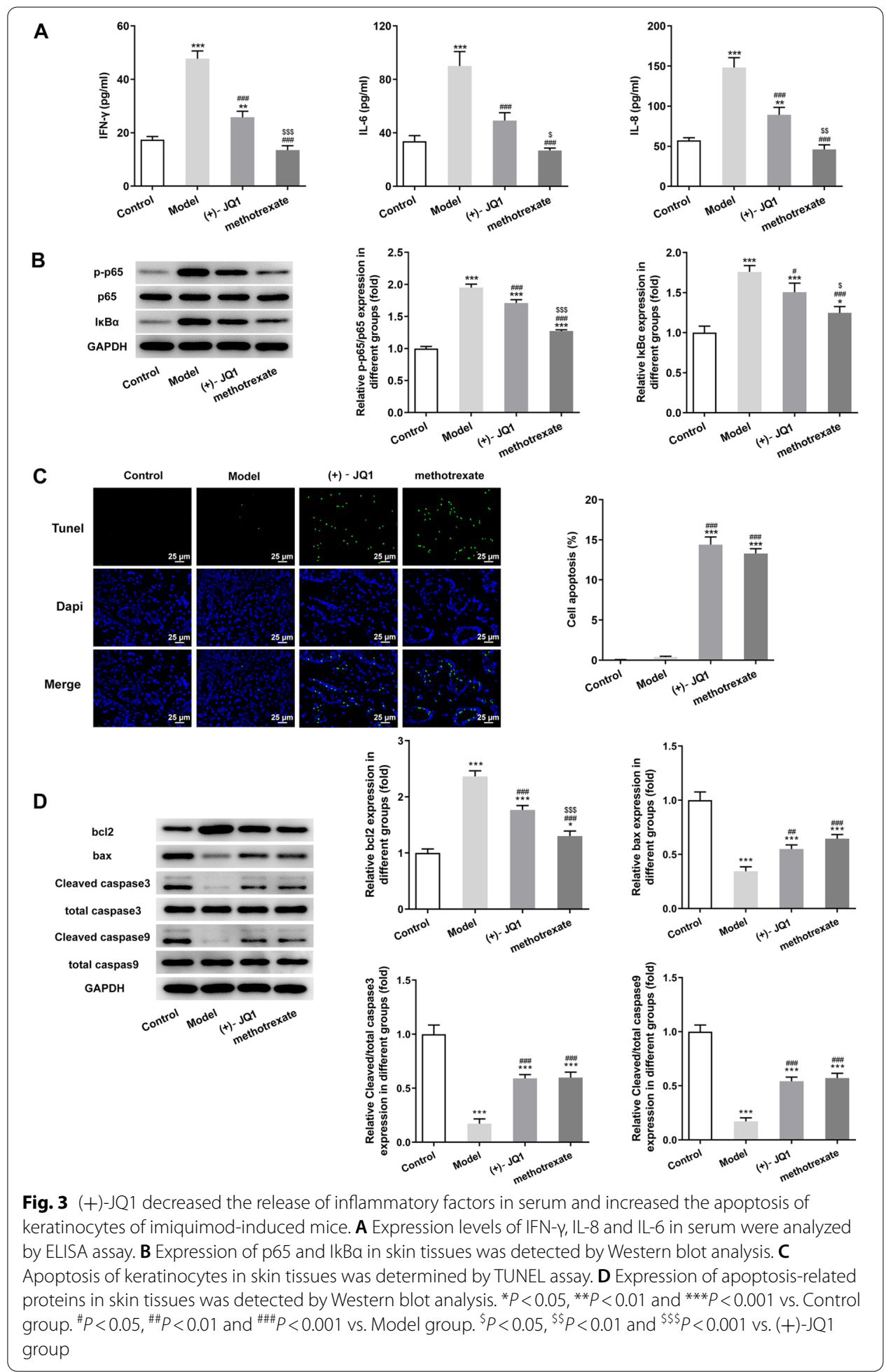




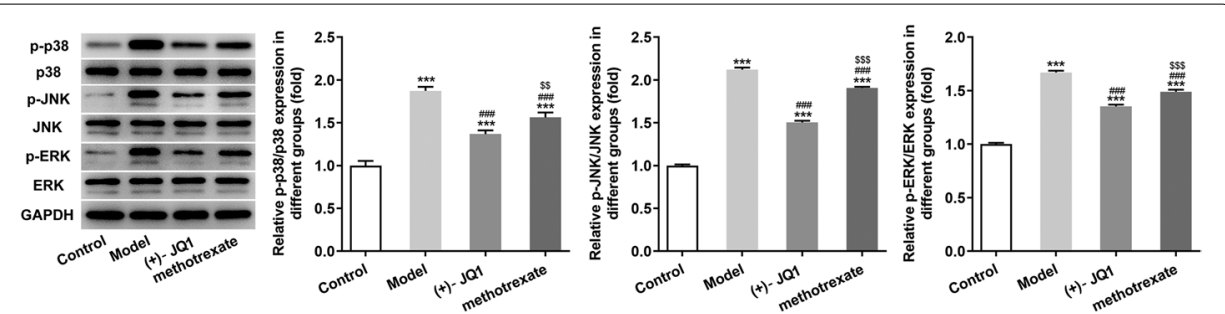

Fig. 4 (+)-JQ1 suppressed the MAPK signaling pathway in imiquimod-induced mice. The expression of MAPK pathway-related proteins in skin tissues was detected by Western blot analysis. ${ }^{* *} P<0.001$ vs. Control group. ${ }^{\# \#} P<0.001$ vs. Model group. ${ }^{\$ \$} P<0.01$ and ${ }^{\$ \$} P<0.001$ vs. (+)-JQ1 group
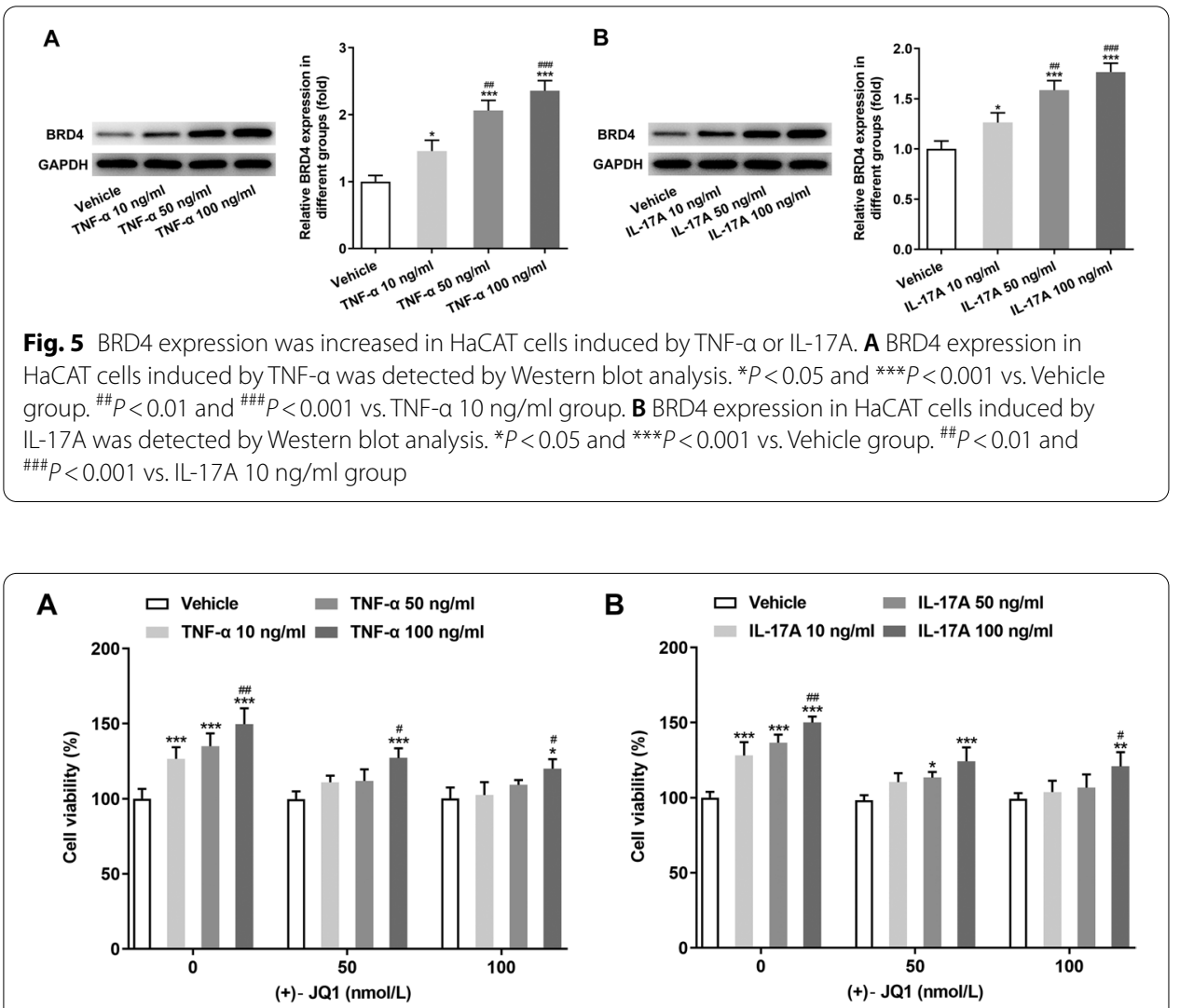

Fig. 6 (+)-JQ1 suppressed the viability of HaCAT cells induced by TNF-a or IL-17A. A Viability of HaCAT cells induced by TNF-a was determined by CCK-8 assay. ${ }^{*} P<0.05$ and ${ }^{* *} P<0.001$ vs. Vehicle group. ${ }^{\#} P<0.05$ and ${ }^{\# \#} P<0.01$ vs. TNF-a $10 \mathrm{ng} / \mathrm{ml}$ group. B Viability of HaCAT cells induced by IL-17A was determined by CCK-8 assay. ${ }^{*} P<0.05,{ }^{*} P<0.01$ and ${ }^{* *} P<0.001$ vs. Vehicle group. ${ }^{\#} P<0.05$ and ${ }^{\# \#} P<0.01 \mathrm{vs}$. IL- $17 \mathrm{~A} 10 \mathrm{ng} / \mathrm{ml}$ group

\section{(+)-JQ1 suppressed the inflammation and proliferation, and promoted the apoptosis of HaCAT cells induced by TNF-a or IL-17A}

The levels of IFN- $\gamma$, IL-8 and IL- 6 in culture supernatant of TNF- $\alpha$ or IL-17A (50 ng/ $\mathrm{ml}$ ) induced HaCAT cells were elevated, which was downregulated by $100 \mathrm{nM}(+)-\mathrm{JQ} 1$ (Fig. 7A, B). The expression of KI67 and PCNA in TNF- $\alpha$ or IL-17A $(50 \mathrm{ng} / \mathrm{ml})$ induced HaCAT cells was also increased, which was decreased by $100 \mathrm{nM}(+)-J Q 1$ (Fig. 7C, D). The apoptosis of HaCAT cells induced by TNF- $\alpha$ or IL-17A was promoted by the treatment of $100 \mathrm{nM}(+)-J Q 1$ (Fig. 8A, C). The bcl2 expression was increased, while the 
A

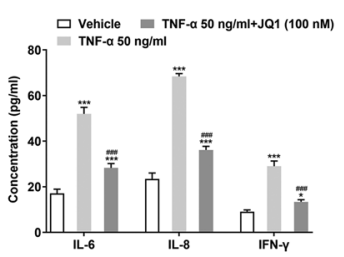

B

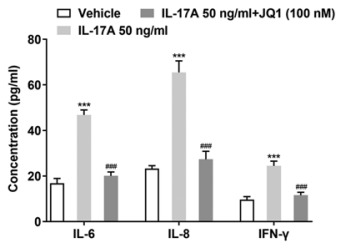

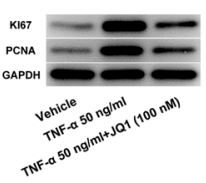

D

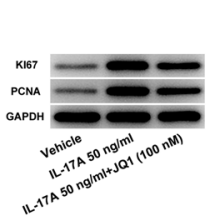

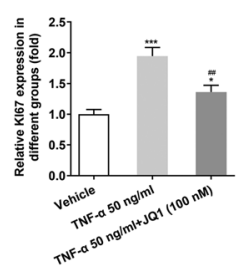
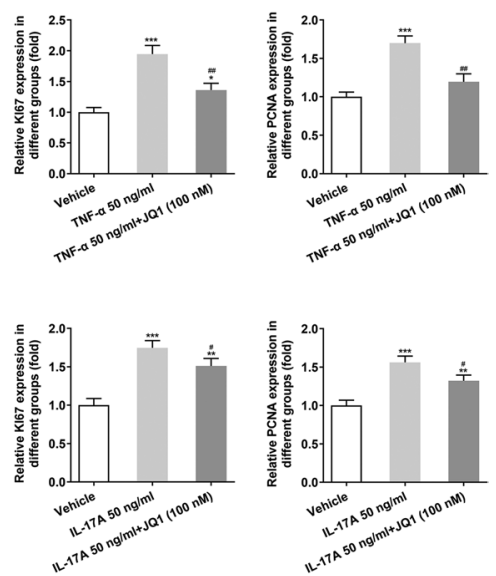

Fig. 7 (+)-JQ1 suppressed the inflammation and proliferation, and promoted the apoptosis of HaCAT cells induced by TNF-a or IL-17A. A Expression levels of IFN- $\gamma$, IL-8 and IL- 6 in culture supernatant of HaCAT cells induced by TNF-a were analyzed by ELISA assay. ${ }^{*} P<0.05$ and ${ }^{* * *} P<0.001$ vs. Vehicle group. ${ }^{\# \#} P<0.001$ vs. TNF-a $50 \mathrm{ng} / \mathrm{ml}$ group. B Expression levels of IFN- $\gamma$, IL-8 and IL-6 in culture supernatant of HaCAT cells induced by IL-17A were analyzed by ELISA assay. ${ }^{* * *} P<0.001$ vs. Vehicle group. ${ }^{\# \#} P<0.001 \mathrm{vs.} \mathrm{IL-17A} 50 \mathrm{ng} / \mathrm{ml}$ group. C Expression of KI67 and PCNA in HaCAT cells induced by TNF-a was detected by Western blot analysis. ${ }^{*} P<0.05$ and ${ }^{* *} P<0.001$ vs. Vehicle group. ${ }^{\# \#} P<0.01$ vs. TNF-a $50 \mathrm{ng} / \mathrm{ml}$ group. D Expression of Kl 67 and PCNA in HaCAT cells induced by IL-17A was detected by Western blot analysis. ${ }^{* *} P<0.01$ and ${ }^{* * *} P<0.001$ vs. Vehicle group. ${ }^{\sharp} P<0.05$ vs. IL-17A $50 \mathrm{ng} / \mathrm{ml}$ group

expression of bax, Cleaved caspase3/total caspase 3 and Cleaved caspase9/total caspase 9 was decreased in TNF- $\alpha$ or IL-17A (50 ng/ml) induced HaCAT cells, which was partially reversed by $100 \mathrm{nM}(+)$-JQ1 (Fig. 8B, D).

(+)-JQ1 suppressed the MAPK signaling pathway in HaCAT cells induced by TNF- $\alpha$ or IL-17A The expression of p-p38/p38, p-JNK/JNK and p-ERK/ERK in TNF- $\alpha$ or IL-17A (50 ng/ $\mathrm{ml}$ ) induced HaCAT cells was increased, which was suppressed by the treatment of $100 \mathrm{nM}(+)$-JQ1 (Fig. 9A, B).

\section{Discussion}

The keratinocytes have receptors for most psoriasis-associated cytokines and chemokines, they represent tissue cells that respond critically to the psoriatic microenvironment. The inflammatory response is accelerated by the production of other cytokines in response to psoriatic cytokines [16-18]. Activated keratinocytes are involved in maintaining and amplifying skin inflammation by releasing inflammatory cytokines and chemokines, which are critical for recruitment of $\mathrm{T}$ cells, neutrophils and inflammatory myeloid dendritic cells [19-21]. In the present study, we found that inflammatory factors (IFN- $\gamma$, IL-8 and IL-6) were increased in serum of imiquimod-induced mice and culture supernatant of HaCAT cells induced by TNF- $\alpha$ or IL-17A.

As a classical cell signal transduction pathway, MAPK/NF- $\mathrm{kB}$ signaling pathway plays an important role in inducing the expression and aggregation of pro-inflammatory factors and anti-inflammatory factors, as well as activating and regulating inflammatory response in psoriasis $[22,23]$. Here, the expression of phosphorylation of NF- $\mathrm{kB}$ (p-p65, IkB $)$ ), MAPK (p-p38, p-JNK and p-ERK) was also activated in skin tissues of 


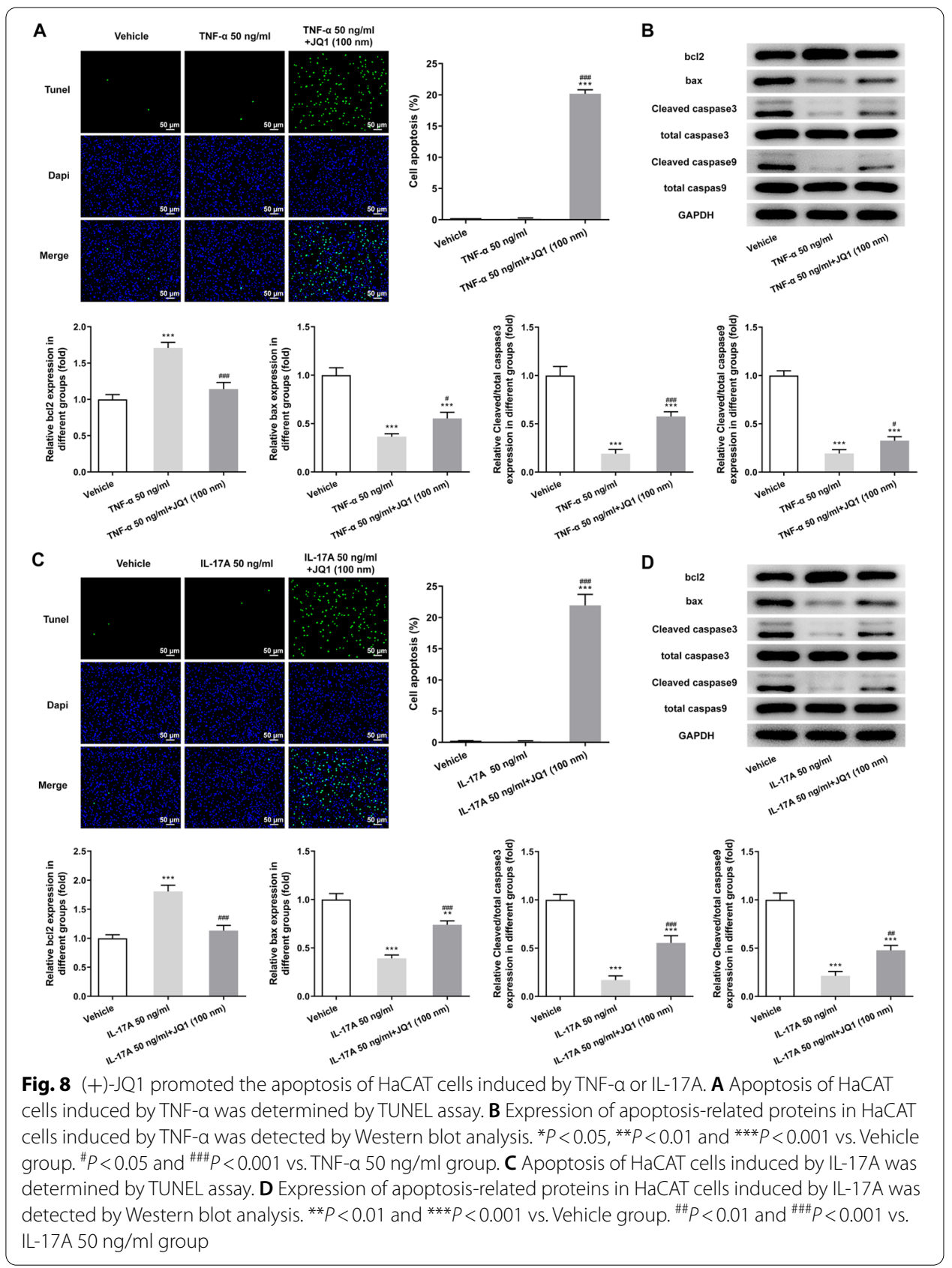

imiquimod-induced mice and HaCAT cells induced by TNF- $\alpha$ or IL-17A. MAPK pathway can also regulate the proliferation and differentiation of keratinocytes. Previous study has shown that MAPK pathway can promote the expression of KI67, PCNA and keratin in keratinocytes, so as to promote the proliferation of keratinocytes [24]. This study indicated that KI67 expression was increased in skin samples of imiquimodinduced mice and the expression of KI67 and PCNA was all increased in HaCAT cells induced by TNF- $\alpha$ or IL-17A.

Zhu et al. found that the blockage of BRD4 could obviously alleviate the inflammation and oxidative stress in aortic banding-operated mice [25]. Downregulation of BRD4 


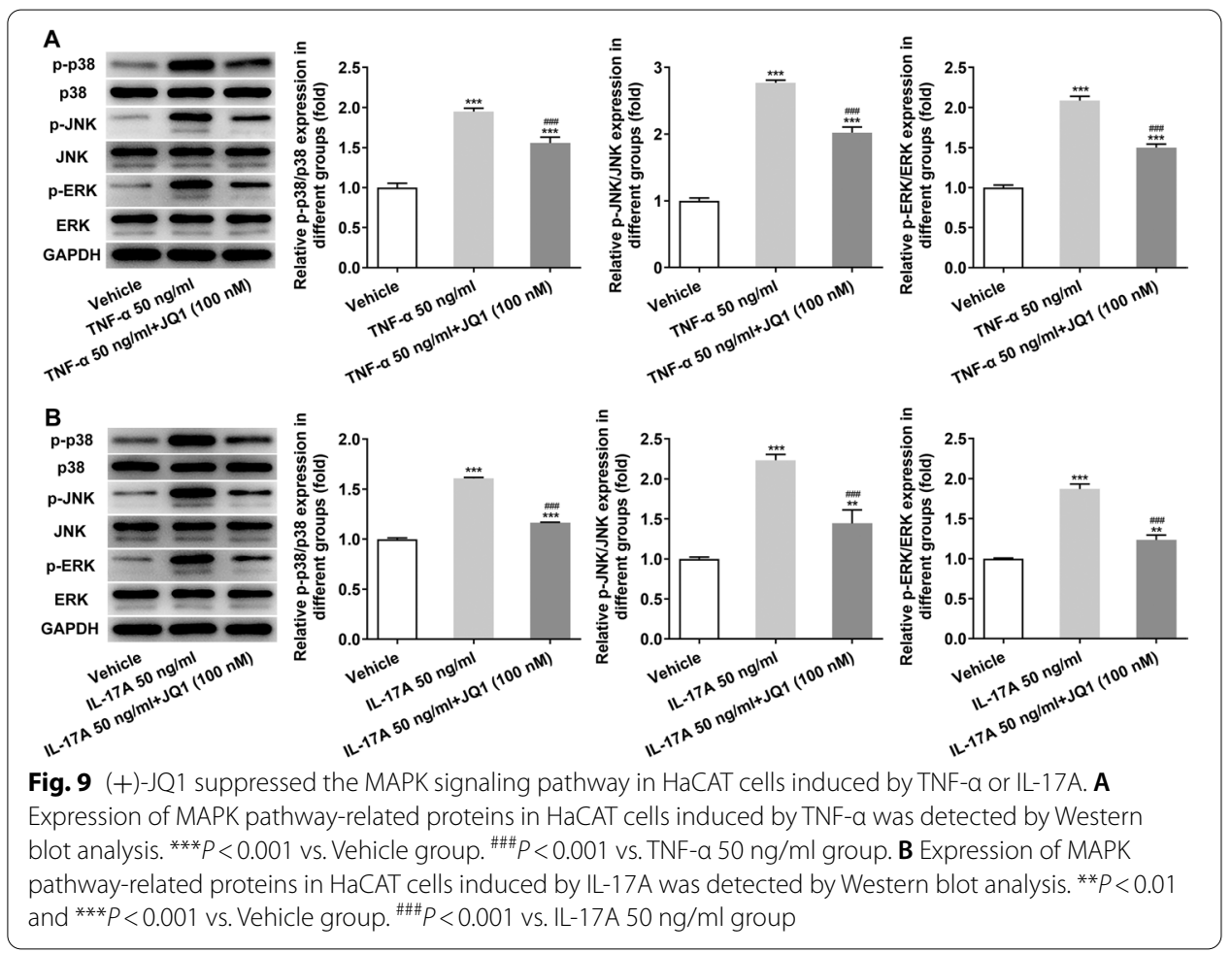

decreased apoptosis and inflammation in BEAS-2B cells induced by cigarette smoke extract [26]. BRD4 could increase transcriptional transactivation activity and stability of NF- $\kappa B$ in the nucleus [27]. BRD4 was necessary for coupling NF- $\kappa B$ to express inflammatory genes, and knockdown of BRD4 alleviated exuberant virus-induced mucosal airway inflammation [28]. Inhibition of BRD4 has been demonstrated to suppress the MAPK signaling pathway in spinal cord ischemia reperfusion injury and diabetic intervertebral disc degeneration [11, 14]. Our study showed that BRD4 expression was increased in skin samples of imiquimod-induced mice and HaCAT cells induced by TNF- $\alpha$ or IL17A. In addition, inhibition of BRD4 decreased the expression levels of inflammatory factors and proliferation-related proteins while increased the expression of apoptosisrelated proteins by suppressing the MAPK signaling pathway.

In conclusion, the findings from our study suggest that BRD4 is functioned in regulating the proliferation and inflammation of keratinocytes through MAPK pathway in psoriasis. Inhibition of BRD4 may possess therapeutic efficacy in the treatment of psoriasis.

\section{Materials and methods}

\section{Imiquimod-induced psoriasis mice model}

Male BALB/c mice aged 6 weeks ate standard animal feed and drink filtered tap water freely for 7 days in a controlled room with the temperature between 22 to $26{ }^{\circ} \mathrm{C}$ and humidity between 40 to $70 \%$. Mice were used to shave their dorsal skins, and imiquimod cream was applied locally once a day for 7 consecutive days to induce psoriasislike dermatitis. (+)-JQ1 $(50 \mathrm{mg} / \mathrm{kg})$ was given intraperitoneal injection on the 7 th day, once a day, totally for 13 days. The mice were sacrificed on the 20th day and skin tissue samples were obtained from the diseased areas. $25 \%$ of the skin was stored with $4 \%$ 
paraformaldehyde at room temperature, while the rest of the skin was stored at $-80{ }^{\circ} \mathrm{C}$. The blood samples were obtained from abdominal aortas and centrifuged at $3000 \mathrm{r}$ / min for 10 min to obtain the serum samples which were stored at $-80^{\circ} \mathrm{C}$. Experimental groups were randomly divided into Control group, Model group, (+)-JQ1 group and methotrexate group $(n=5)$. The animal experiment was approved and supervised by the Animal Care and Use Committee and the Animal Ethics Committee at Shandong Provincial Qianfoshan Hospital, Cheeloo College of Medicine, Shandong University.

\section{Haematoxylin-eosin staining}

Paraffin sections of skin tissues were stained by hematoxylin and eosin (H\&E; Beyotime), and pathological skin changes were observed under a light microscope (Olympus Corporation; magnification, $100 \times$ ).

\section{Psoriasis area and severity index (PASI)}

PASI score was adopted for the degree of the three indexes (Erythema, Induration and Desquamation) at the skin lesions of mice, and the sum of the scores of the three indexes was the total score. PASI scoring criteria: none (0): no erythema scales on the surface; mild (1): some lesions were covered with scales, mainly fine scales, slightly higher than the normal skin surface, reddish; moderate (2): most lesions were completely or incompletely covered with scales, scales were patchy, moderately raised, the edge of the plaque was round or sloping, red; severe (3): almost all lesions covered with scales, scales thick layer, thick lesions, prominent protuberance, crimson; extremely severe (4): all lesions. The total score was the sum of the three indexes ( $0 \sim 12$ points).

\section{Immunohistochemical analysis}

The paraffin sections were dewaxened, hydrated, sealed, and cold-repaired with antigen repair solution. The sections were incubated with $\mathrm{KI} 67$ antibody (Abcam) at $4{ }^{\circ} \mathrm{C}$ overnight. After placed at room temperature for $30 \mathrm{~min}$ the next day, the sections were first added with reaction enhanced solution for $10 \mathrm{~min}$, followed by the treatment with secondary antibody for $20 \mathrm{~min}$ at room temperature. Then, sections were colored with the treatment of DAB for 5-8 min, counterstained with hematoxylin for $20 \mathrm{~s}$, dehydrated and sealed. Finally, KI67 expression was observed under a light microscope (Olympus Corporation; magnification, $100 \times$ ).

\section{Cell culture and cell induction}

Human immortal keratinocyte line (HaCAT) was provided from CoBioer (Nanjing, China). HaCAT cells were cultured in Dulbecco's modified Eagle's medium (DMEM) containing $10 \%$ fetal bovine serum (FBS; Thermo Fisher Scientific, Inc.) at $37{ }^{\circ} \mathrm{C}$ of $5 \%$ $\mathrm{CO}_{2}$.

HaCAT cells were, respectively, induced by TNF- $\alpha$ or IL-17A at concentrations of $10 \mathrm{ng} / \mathrm{ml}, 50 \mathrm{ng} / \mathrm{ml}$ and $100 \mathrm{ng} / \mathrm{ml}$ for $24 \mathrm{~h}$ to construct the vitro model of psoriasis.

\section{ELISA assay}

The serum was dissolved at room temperature and mixed well. The cell culture supernatant of HaCAT cells after indicated treatment was obtained after centrifugation (1000 
$\mathrm{r} / \mathrm{min}, 10 \mathrm{~min}$ ). The levels of IFN- $\gamma$, IL-8 and IL- 6 in the mice serum were detected by Mouse IFN- $\gamma$ ELISA Kit (Beyotime), Mouse IL-8 ELISA Kit (Wuhan Saipei Biotechnology Co., Ltd) and Mouse IL-6 ELISA Kit (Beyotime) and the levels of IFN- $\gamma$, IL-8 and IL-6 in the culture supernatant of HaCAT cells were detected by Human ELISA Kits (Beyotime).

\section{TUNEL assay}

Keratinocyte apoptosis at the back of mice skin was detected by terminal deoxynucleotidyl transferase dUTP nick end labeling (TUNEL) assay in accordance with the manufacturer protocol (Roche, USA). After washed with PBS for three times, skin sections were incubated with DAPI for $10 \mathrm{~min}$, which were then observed and photographed using a fluorescence microscope in a mounting medium (Olympus Corporation; magnification, $400 \times)$.

\section{Western blot analysis}

Total protein lysates in the rest of frozen skin samples and HaCAT cells after indicated treatment were obtained with RIPA buffer. A bicinchoninic acid (BCA) protein assay kit (Beyotime) was applied to detect protein concentration. $50 \mu \mathrm{g}$ proteins were separated on $12 \%$ gel with sodium dodecyl sulfate polyacrylamide gel electrophoresis (SDS-PAGE) and transferred to a polyvinylidene fluoride (PVDF) membrane. Blocked with 5\% milk for $2 \mathrm{~h}$ at room temperature, the membrane was incubated with the primary antibodies of BRD4, p-p65, IkB $\alpha, p 65$, bcl2, bax, cleaved caspase3, cleaved caspase9, total caspase3, total caspase9, p-P38, p-JNK, p-ERK, P38, JNK, ERK, KI67, PCNA and GAPDH at $4{ }^{\circ} \mathrm{C}$ overnight. After washing of tris-buffered saline with Tween (TBST) for three times, the membranes were incubated with the HRP-labeled secondary antibody at room temperature for $1 \mathrm{~h}$. The protein bands were detected by enhanced chemiluminescence (ECL; Millipore, USA) and quantified using Image-Pro Plus software (version 6.0; Media Cybernetics, Inc.).

\section{CCK-8 assay}

HaCAT cells were seeded at $5 \times 10^{3}$ cells/well in the 96-well plate and cultured for overnight at $37^{\circ} \mathrm{C}$. HaCAT cells were treated with TNF- $\alpha$ or IL-17A $(10 \mathrm{ng} / \mathrm{ml}, 50 \mathrm{ng} / \mathrm{ml}$ and $100 \mathrm{ng} / \mathrm{ml}$ ) adding or not adding (+)-JQ1 (50 nmol/l and $100 \mathrm{nmol} / \mathrm{l})$ for $24 \mathrm{~h} .10 \mu \mathrm{l}$ CCK-8 solution (Beyotime) was added to each well of 96-well plate which was incubated at $37^{\circ} \mathrm{C}$ for $1 \mathrm{~h}$. The optical density (OD) value at $450 \mathrm{~nm}$ was determined with an enzyme-linked immunosorbent assay reader. (+)-JQ1 is a BRD4 inhibitor.

\section{Statistical analysis}

Statistical analysis software Graphpad8.0 was used, experimental data were represented by mean \pm standard deviation (SD). Differences between the two groups were calculated by Student- $t$ test. One-way ANOVA with Tukey's post hoc test was used for the comparison of mean values when more than two groups. Differences were statistically significant when $P<0.05$. 


\section{Authors' contributions}

XS and PY conceived this project. XS performed all the experiments, made statistical analysis of experimental data and wrote the whole manuscript. PY revised the manuscript. Both authors read and approved the final manuscript.

\section{Funding}

Not applicable.

Availability of data and materials

The experimental data will be available on the request.

\section{Declarations}

\section{Ethics approval and consent to participate}

The animal experiment was approved and supervised by the Animal Care and Use Committee and the Animal Ethics Committee at Shandong Provincial Qianfoshan Hospital, Cheeloo College of Medicine, Shandong University.

\section{Consent for publication}

Not applicable.

\section{Competing interests}

The authors declare they have no competing interests.

\section{Author details}

${ }^{1}$ Department of Dermatology, Shandong Provincial Qianfoshan Hospital, Cheeloo College of Medicine, Shandong University, Jinan 250014, Shandong, China. ${ }^{2}$ Department of Dermatology, The First Affiliated Hospital of Shandong First Medical University \& Shandong Provincial Qianfoshan Hospital, Jinan Clinical Research Center for Tissue Engineering Skin Regeneration and Wound Repair, 16766 Jingshi Road, Jinan 250014, Shandong, China.

Received: 13 May 2021 Accepted: 5 October 2021

Published online: 21 October 2021

\section{References}

1. NN Mehta P Krishnamoorthy Y Yu O Khan A Raper A Voorhees Van AB Troxel JM Gelfand 2012 The impact of psoriasis on 10-year Framingham risk J Am Acad Dermatol 674796798

2. U Praveenkumar S Ganguly L Ray SK Nanda S Kuruvila 2016 Prevalence of metabolic syndrome in psoriasis patients and its relation to disease duration: a hospital based case-control study J Clin Diagn Res 1020105

3. JL Sanchez-Carazo JL López-Estebaranz C Guisado 2014 Comorbidities and health-related quality of life in Spanish patients with moderate to severe psoriasis: a cross-sectional study (Arizona study) J Dermatol 418673678

4. MA Lowes AM Bowcock JG Krueger 2007 Pathogenesis and therapy of psoriasis Nature 4457130866873

5. A Brandon A Mufti R Gary Sibbald 2019 Diagnosis and management of cutaneous psoriasis: a review Adv Skin Wound Care 3225869

6. LL Fu M Tian X Li JJ Li J Huang L Ouyang Y Zhang B Liu 2015 Inhibition of BET bromodomains as a therapeutic strategy for cancer drug discovery Oncotarget 6855015516

7. RW Schnepp JM Maris 2013 Targeting MYCN: a good BET for improving neuroblastoma therapy? Cancer Discov 33 255257

8. X Xang R Peng Y Ren S Apparsundaram J Deguzman CM Bauer AF Hoffman S Hamilton Z Liang H Zeng 2013 BET bromodomain proteins mediate downstream signaling events following growth factor stimulation in human lung fibroblasts and are involved in bleomycin-induced pulmonary fibrosis Mol Pharmacol 831283293

9. Y Ren Y Zhang Z Wang C Wang H Zhang Y Wang Z Zhao 2019 Role of Brd4 in the production of inflammatory cytokines in mouse macrophages treated with titanium particles Can J Physiol Pharmacol 971110281034

10. Y Zhou Y Gu J Liu 2019 BRD4 suppression alleviates cerebral ischemia-induced brain injury by blocking glial activation via the inhibition of inflammatory response and pyroptosis Biochem Biophys Res Commun 5193481488

11. J Wang J Chen H Jin D Lin Y Chen X Chen B Wang S Hu Y Wu Y Wu 2019 BRD4 inhibition attenuates inflammatory response in microglia and facilitates recovery after spinal cord injury in rats J Cell Mol Med 23532143223

12. K Zhang Y Xu 2020 Suppressing BRD4 exhibits protective effects against vincristine-induced peripheral neuropathy by alleviating inflammation and oxidative stress Biochem Biophys Res Commun 5322271279

13. M Pan Y Huang X Zhu X Lin D Luo 2019 miR-125b-mediated regulation of cell proliferation through the Jagged-1/ Notch signaling pathway by inhibiting BRD4 expression in psoriasis Mol Med Rep 19652275236

14. J Wang J Hu X Chen C Huang J Lin Z Shao M Gu Y Wu N Tian W Gao 2019 BRD4 inhibition regulates MAPK, NF-kB signals, and autophagy to suppress MMP-13 expression in diabetic intervertebral disc degeneration Faseb j 3310 1155511566

15. S Sugihara S Sugimoto K Tachibana M Kobashi H Nomura T Miyake Y Hirai O Yamasaki S Morizane 2019 TNF-a and IL-17A induce the expression of lympho-epithelial Kazal-type inhibitor in epidermal keratinocytes J Dermatol Sci 96 12632

16. L Fits van der S Mourits JS Voerman M Kant L Boon JD Laman F Cornelissen AM Mus E Florencia EP Prens E Lubberts 2009 Imiquimod-induced psoriasis-like skin inflammation in mice is mediated via the IL-23/IL-17 axis J Immunol 182 958365845

17. HL Ha H Wang P Pisitkun JC Kim I Tassi W Tang MI Morasso MC Udey U Siebenlist 2014 IL-17 drives psoriatic inflammation via distinct, target cell-specific mechanisms Proc Natl Acad Sci U S A 11133 E3422 3431 
18. Y Cai X Shen C Ding C Qi K Li X Li VR Jala HG Zhang TWang J Zheng J Yan 2011 Pivotal role of dermal IL-17-producing $\gamma \delta$ T cells in skin inflammation Immunity 354596610

19. K Sato M Takaishi S Tokuoka S Sano 2014 Involvement of TNF-a converting enzyme in the development of psoriasislike lesions in a mouse model PLOS ONE 911 e112408

20. A Blauvelt 2017 IL-6 Differs from TNF-a: Unpredicted Clinical Effects Caused by IL-6 Blockade in Psoriasis J Invest Dermatol 1373541542

21. SM Ferrari I Ruffilli M Colaci A Antonelli C Ferri P Fallahi 2015 CXCL10 in psoriasis Adv Med Sci 602349354

22. F Xu J Xu X Xiong Y Deng 2019 Salidroside inhibits MAPK, NF-KB, and STAT3 pathways in psoriasis-associated oxidative stress via SIRT1 activation Redox Rep 2417074

23. A Liu W Zhao B Zhang Y Tu Q Wang J Li 2020 Cimifugin ameliorates imiquimod-induced psoriasis by inhibiting oxidative stress and inflammation via NF-KB/MAPK pathway Biosci Rep 4060200471

24. G Yang S Li Y Yang L Yuan P Wang H Zhao C Ho C Lin 2018 Nobiletin and 5-Hydroxy-6,7,8,3',4'-pentamethoxyflavone Ameliorate 12- O-Tetradecanoylphorbol-13-acetate-Induced Psoriasis-Like Mouse Skin Lesions by Regulating the Expression of Ki-67 and Proliferating Cell Nuclear Antigen and the Differentiation of CD4 T Cells through MitogenActivated Protein Kinase Signaling Pathways J Agric Food Chem 663182998306

25. W Zhu RD Wu YG Lv YM Liu H Huang JQ Xu 2020 BRD4 blockage alleviates pathological cardiac hypertrophy through the suppression of fibrosis and inflammation via reducing ROS generation Biomed Pharmacother 121 109368

26. X Liu J Wang H Luo C Xu X Chen R Zhang 2020 MiR-218 Inhibits CSE-Induced Apoptosis and Inflammation in BEAS2B by Targeting BRD4 Int J Chron Obstruct Pulmon Dis 1534073416

27. A Hajmirza A Emadali A Gauthier O Casasnovas R Gressin M Callanan 2018 BET Family Protein BRD4: An Emerging Actor in NFKB Signaling in Inflammation and Cancer Biomedicines 6116

28. B Tian J Yang Y Zhao T Ivanciuc H Sun RP Garofalo AR Brasier 2017 BRD4 Couples NF-kB/RelA with Airway Inflammation and the IRF-RIG-I Amplification Loop in Respiratory Syncytial Virus Infection J Virol 916 e00007 00017

\section{Publisher's Note}

Springer Nature remains neutral with regard to jurisdictional claims in published maps and institutional affiliations.

- fast, convenient online submission

- thorough peer review by experienced researchers in your field

- rapid publication on acceptance

- support for research data, including large and complex data types

- gold Open Access which fosters wider collaboration and increased citations

- maximum visibility for your research: over 100M website views per year

At BMC, research is always in progress.

Learn more biomedcentral.com/submissions 